\title{
Effects of topical bevacizumab application on early bleb failure after trabeculectomy: observational case series
}

This article was published in the following Dove Press journal:

Clinical Ophthalmology

24 September 2013

Number of times this article has been viewed

Justyna Klos-Rola

Maria Tulidowicz-Bielak

Tomasz Zarnowski

Department of Ophthalmology, Medical University of Lublin, Lublin, Poland
Correspondence: Justyna Klos-Rola Department of Ophthalmology, Medical University of Lublin, I Chmielna St, 20079 Lublin, Poland Tel +488 I532 6149

Fax +488 I532 4827 Email jklosrola@gmail.com
Background: The aim of this study was to evaluate the influence of topical bevacizumab on the formation and function of filtering blebs in eyes with early bleb failure after antiglaucoma surgery.

Methods: Of all patients who underwent mitomycin-augmented trabeculectomy for glaucoma in the Department of Ophthalmology at the Medical University in Lublin, Poland, between March 2009 and March 2010, a total of 21 eyes from 20 patients with injected filtration bleb $9.8 \pm 4.7$ days after surgery were included in this observational case series. All patients were treated with standard steroid therapy and topical bevacizumab $5 \mathrm{mg} / \mathrm{mL}$ five times a day for $20.9 \pm 9.8$ days. Patients were followed up every other day, and a full eye examination was performed 14, 30, 60, and 180 days after initiation of treatment. Blebs were evaluated for vascularity by slit-lamp examination with concomitant photographic documentation and intraocular pressure measurement.

Results: Elevated functional bleb with significantly reduced vascularity was present in 16 eyes, and was flat and nonfunctional in five eyes. Intraocular pressure in all eyes decreased from a mean of $26.6 \pm 9.6 \mathrm{mmHg}$ before surgery to $14.6 \pm 7.7 \mathrm{mmHg}$ and $15.8 \pm 8.3 \mathrm{mmHg}$ at 2 and 6 months after surgery, respectively. Filtration bleb leak was noted in three eyes while on treatment with bevacizumab.

Conclusion: Topical application of bevacizumab might favor functional bleb formation after trabeculectomy in eyes with a high risk of failure.

Keywords: glaucoma, trabeculectomy, bleb failure, bevacizumab

\section{Introduction}

Trabeculectomy remains a standard filtration procedure in glaucoma surgery. It aims to decrease intraocular pressure (IOP) by constant shunting of aqueous fluid from the anterior chamber into the subconjunctival space, with subsequent creation of a filtering bleb. ${ }^{1}$ Filtering bleb insufficiency as a result of excessive scarring attributable to proliferation of fibroblasts and subconjunctival fibrosis is one of the main reasons for treatment failure. ${ }^{2}$ In this respect, trabeculectomy differs from other surgical procedures because its success relies on inhibition of wound healing. ${ }^{1}$

One of the crucial steps in physiologic wound healing is angiogenesis. ${ }^{3}$ Therefore, antiangiogenic agents might be a promising therapeutic strategy aimed at inhibition of postoperative wound healing after trabeculectomy. One of the most important proangiogenic substances involved in both physiologic and pathologic angiogenesis is vascular endothelial growth factor (VEGF). VEGF is one member of a group of substances among which VEGF-A is considered a prototype for a whole family. ${ }^{4}$ 
Bevacizumab (Avastin ${ }^{\circledR}$, Roche, Basel, Switzerland) is a humanized monoclonal antibody against all isoforms of VEGF-A, and in 2004 was the first antiangiogenic substance approved by the US Food and Drug Administration for therapeutic use in oncology. ${ }^{4-6}$ In addition to being used in the treatment of cancer, bevacizumab is currently being used offlabel in ophthalmology to treat various pathologies involving neovascularization. Intravitreal injections are proposed as a part of the therapeutic protocols for age-related macular degeneration, myopia, premature retinopathy, central retinal vein thrombosis, and retinal vascular malformations. ${ }^{5,7}$

Anterior chamber injections are recommended for iris neovascularization, with topical application or subconjunctival injections being advocated for corneal neovascularization or recurrent pterygium. ${ }^{6,8,9}$ Attempts to treat glaucoma with subconjunctival injections of bevacizumab have also been described. ${ }^{10}$ Importantly, no significant side effects in the posterior ${ }^{11}$ or anterior ${ }^{12}$ segments of the eye have been reported to date. Based on the available data, we elected to use topical bevacizumab as a therapeutic modality after filtration procedures in order to elucidate its potential influence on wound healing and the morphology of the filtering bleb.

\section{Materials and methods}

The study protocol was approved by the local ethics committee and adhered to the tenets of the Declaration of Helsinki. Of all patients who were treated surgically for glaucoma in the department of ophthalmology, Medical University in Lublin, between March 2009 and March 2010, a total of 21 eyes (from 20 patients) with primary open angle glaucoma, primary closure angle glaucoma, or capsular glaucoma were included in the study. Twenty eyes underwent trabeculectomy with mitomycin $\mathrm{C}$, and the remaining eye underwent a filtration procedure with implantation of a drainage device (Express $^{\mathrm{TM}}$, Atrium Medical Corporation, Hudson, NH, USA) under a scleral flap. Inclusion criteria were the presence of an injected filtration bleb regardless of IOP levels and a poor prognosis, ie, adequate to grades H0, H1, E0, E1, and V3, and V4 of the Indiana Bleb Appearance Grading Scale. ${ }^{13}$ Our cohort consisted of 12 females and nine males of mean age $67.8 \pm 11.2$ years. Detailed demographic data are shown in Table 1.

\section{Surgical technique}

After peribulbar anesthesia, a fornix-based conjunctival flap was prepared. Hemostasis was achieved using wet field cautery. A rectangular scleral flap measuring $4 \times 3 \mathrm{~mm}$ was then dissected to a depth of one half the scleral thickness until the entire corneoscleral limbus was exposed. Two small $4 \mathrm{~mm} \times 3 \mathrm{~mm}$ rectangular fragments of surgical sponge were then saturated with a $0.3 \mathrm{mg} / \mathrm{dL}$ solution of mitomycin $\mathrm{C}$ in saline; one was placed under the scleral flap and the other over the scleral flap under Tenon's capsule for 3 minutes. The exposure site was irrigated copiously with saline. Trabeculectomy was performed using 1-2 bites with a Pierce punch, after which peripheral iridectomy was performed. The scleral flap was closed with two fixed and two releasable 10-0 nylon sutures in the standard manner. Next, Tenon's capsule and the conjunctiva were each tightly closed with single 10-0 nylon sutures.

In addition to standard postoperative therapy of dexamethasone five times a day in decreasing doses for up to 6 weeks, an antibiotic (Oftaquix ${ }^{\circledR}$, Santen $\mathrm{GmbH}$, Munchen, Germany) five times a day, and 1\% topical atropine (Atropinum Sulfuricum 1\%, Polfa Warsaw, Poland) twice a day for 10 days, all study patients received topical bevacizumab five times a day. Topical drops were titrated to $5 \mathrm{mg} / \mathrm{mL}$ with sterile saline from a commercially available bevacizumab solution and were subsequently stored at $4^{\circ} \mathrm{C}$. Patients were followed up every other day, and a full eye examination was performed on days 14, 30, 60, and 180 after initialization of treatment. Standard examination included IOP measurement, assessment of best corrected visual acuity, slit-lamp examination of the anterior and posterior segments of the eye, and visual fields at 30 and 180 days after surgery. Visits were scheduled more often in some cases. Blebs were evaluated for vascularity by the same surgeon using the slit-lamp with concomitant photographic documentation.

\section{Results}

Patients were enrolled for the study if they met inclusion criteria, with 21 eyes qualifying at a mean of $9.8 \pm 4.7$ (4-20) days after surgery. Bevacizumab was administered for up to 15 days in 11 eyes, and in 10 eyes we extended therapy because of poor bleb morphology or increased IOP. The mean duration of treatment for the whole group was $20.9 \pm 9.8$ days, with the shortest treatment period being 11 days and the longest being 43 days. By the end of treatment, a pale, elevated, and functional filtration bleb was present in 16 eyes (Figure 1). In five cases (JB, FS, JC, ZS, KW) deemed to be failures at the end of treatment with bevacizumab, a pale yet circumscribed, flat, and nonfiltering bleb was present (Figure 2). Because of elevated IOP (38 $\mathrm{mmHg}$ ) ten weeks after surgery, one of the patients eventually underwent postoperative wound revision, 
Table I Detailed demographic and treatment data for the study cohort

\begin{tabular}{|c|c|c|c|c|c|c|c|c|}
\hline Patient & Gender & $\begin{array}{l}\text { Age, } \\
\text { years }\end{array}$ & Diagnosis & Surgery & $\begin{array}{l}\text { Initiation of } \\
\text { treatment }\end{array}$ & $\begin{array}{l}\text { Duration of } \\
\text { treatment }\end{array}$ & $\begin{array}{l}\text { Outcome of } \\
\text { treatment }\end{array}$ & $\begin{array}{l}\text { Previous } \\
\text { procedures }\end{array}$ \\
\hline MP & $\mathrm{F}$ & 76 & POAG & $\begin{array}{l}\text { MMC augmented } \\
\text { trabeculectomy }\end{array}$ & 8 days after surgery & 18 days & Success & No \\
\hline KL & M & 50 & POAG & $\begin{array}{l}\text { MMC augmented } \\
\text { trabeculectomy }\end{array}$ & 9 days after surgery & 15 days & Success & No \\
\hline JL & M & 60 & POAG & $\begin{array}{l}\text { MMC augmented } \\
\text { trabeculectomy }\end{array}$ & 4 days after surgery & 13 days & Success & No \\
\hline $\mathrm{JB}$ & $\mathrm{F}$ & 71 & POAG & $\begin{array}{l}\text { MMC augmented } \\
\text { trabeculectomy }\end{array}$ & 6 days after surgery & 16 days & Failure & Yes \\
\hline ED & $\mathrm{F}$ & 57 & POAG & $\begin{array}{l}\text { MMC augmented } \\
\text { trabeculectomy }\end{array}$ & 8 days after surgery & 19 days & Success & No \\
\hline MK & M & 55 & POAG & $\begin{array}{l}\text { MMC augmented } \\
\text { trabeculectomy }\end{array}$ & 8 days after surgery & 22 days & Success & No \\
\hline CG & $\mathrm{F}$ & 67 & POAG & $\begin{array}{l}\text { MMC augmented } \\
\text { trabeculectomy }\end{array}$ & 7 days after surgery & 14 days & Success & No \\
\hline HD & $\mathrm{F}$ & 72 & CG (PEX) & $\begin{array}{l}\text { MMC augmented } \\
\text { trabeculectomy }\end{array}$ & 7 days after surgery & 20 days & Success & No \\
\hline FS & M & 82 & POAG & $\begin{array}{l}\text { MMC augmented } \\
\text { trabeculectomy }\end{array}$ & 10 days after surgery & 15 days & Failure & No \\
\hline TL & M & 63 & CG (PEX) & $\begin{array}{l}\text { MMC augmented } \\
\text { trabeculectomy }\end{array}$ & 16 days after surgery & 14 days & Success & No \\
\hline $\mathrm{JC}$ & $\mathrm{F}$ & 78 & POAG & $\begin{array}{l}\text { MMC augmented } \\
\text { trabeculectomy } \\
\text { with phaco and IOL }\end{array}$ & 9 days after surgery & 26 days & Failure & No \\
\hline $\mathrm{JC}$ & $\mathrm{F}$ & 78 & POAG & $\begin{array}{l}\text { MMC augmented } \\
\text { trabeculectomy } \\
\text { with phaco and IOL }\end{array}$ & I5 days after surgery & 15 days & Success & No \\
\hline ZS & $\mathrm{F}$ & 65 & CG (PEX) & $\begin{array}{l}\text { MMC augmented } \\
\text { trabeculectomy } \\
\text { with phaco and IOL }\end{array}$ & 19 days after surgery & 28 days & Failure & No \\
\hline KW & $\mathrm{F}$ & 64 & PCAG & $\begin{array}{l}\text { MMC augmented } \\
\text { trabeculectomy } \\
\text { with phaco and IOL }\end{array}$ & 7 days after surgery & 14 days & Failure & No \\
\hline GN & $\mathrm{F}$ & 87 & POAG & $\begin{array}{l}\text { MMC augmented } \\
\text { trabeculectomy } \\
\text { with phaco and IOL }\end{array}$ & 10 days after surgery & 30 days & Success & No \\
\hline LK & M & 53 & PCAG & $\begin{array}{l}\text { MMC augmented } \\
\text { trabeculectomy } \\
\text { with phaco and IOL }\end{array}$ & 12 days after surgery & 15 days & Success & No \\
\hline KK & $\mathrm{F}$ & 81 & POAG & $\begin{array}{l}\text { MMC augmented } \\
\text { trabeculectomy } \\
\text { with phaco and IOL }\end{array}$ & 16 days after surgery & 41 days & Success & No \\
\hline $\mathrm{JL}$ & M & 71 & POAG & $\begin{array}{l}\text { MMC augmented } \\
\text { trabeculectomy } \\
\text { with phaco and IOL }\end{array}$ & 5 days after surgery & 38 days & Success & No \\
\hline AK & $M$ & 47 & POAG & $\begin{array}{l}\text { MMC augmented } \\
\text { trabeculectomy } \\
\text { with phaco and IOL }\end{array}$ & 4 days after surgery & 43 days & Success & No \\
\hline $\mathrm{JC}$ & M & 76 & POAG & $\begin{array}{l}\text { MMC augmented } \\
\text { trabeculectomy } \\
\text { with phaco and IOL }\end{array}$ & 20 days after surgery & 12 days & Success & No \\
\hline WA & $\mathrm{F}$ & 70 & CG (PEX) & $\begin{array}{l}\text { Ex-press } \\
\text { implantation } \\
\text { with MMC }\end{array}$ & 7 days after surgery & II days & Success & Yes \\
\hline
\end{tabular}

Abbreviations: M, male; F, female; PCAG, primary closure angle glaucoma: POAG, primary open angle glaucoma; CG, capsular glaucoma; PEX, pseudoexfoliation syndrome; MMC, mitomycin C; phaco, phacoemulsification; IOL, intraocular lens. 


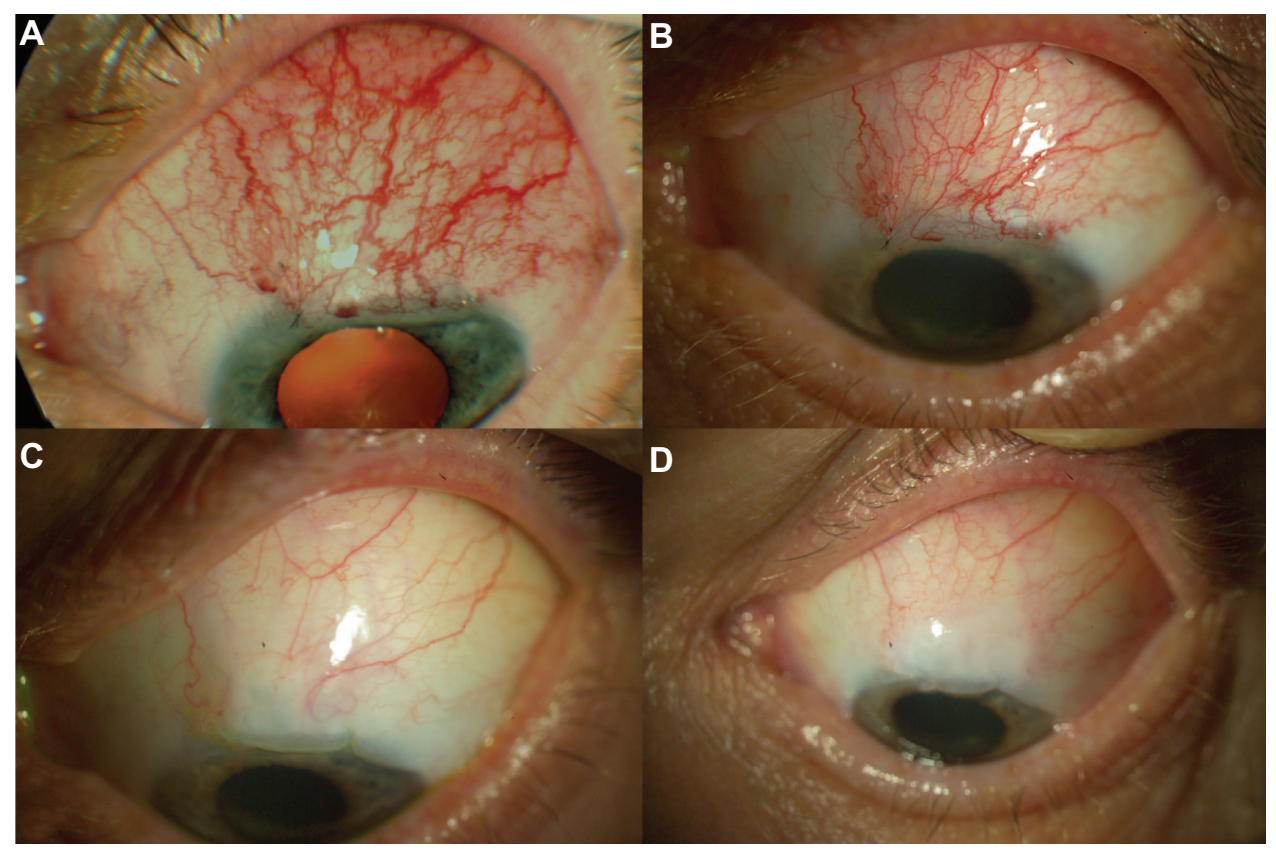

Figure I Successful treatment of early bleb failure with topical bevacizumab in patient 3. (A) Flat and injected bleb prior to bevacizumab application, (B) 7 days after topical administration of bevacizumab, (C) 2 months after topical administration of bevacizumab, and (D) 6 months after topical administration of bevacizumab, revealing a pale, elevated, and functional bleb.

and the other patient is still under surveillance. However, it should be noted that all of the patients in our cohort had pale avascular blebs, whether functional or not, during long-term follow-up.

The mean IOP in all of the eyes was $26.6 \pm 9.6 \mathrm{mmHg}$ prior to surgery, $16.9 \pm 8.4 \mathrm{mmHg}$ at the beginning of treatment with bevacizumab, and $14.6 \pm 7.7 \mathrm{mmHg}$ and $15.8 \pm 8.3 \mathrm{mmHg}$ at 2 and 6 months after surgery, respectively. Detailed IOP values are summarized in Table 2.

Filtration bleb leak occurred in three eyes treated with bevacizumab. Treatment with bevacizumab was terminated on day 14 in one eye because of a positive Seidel test

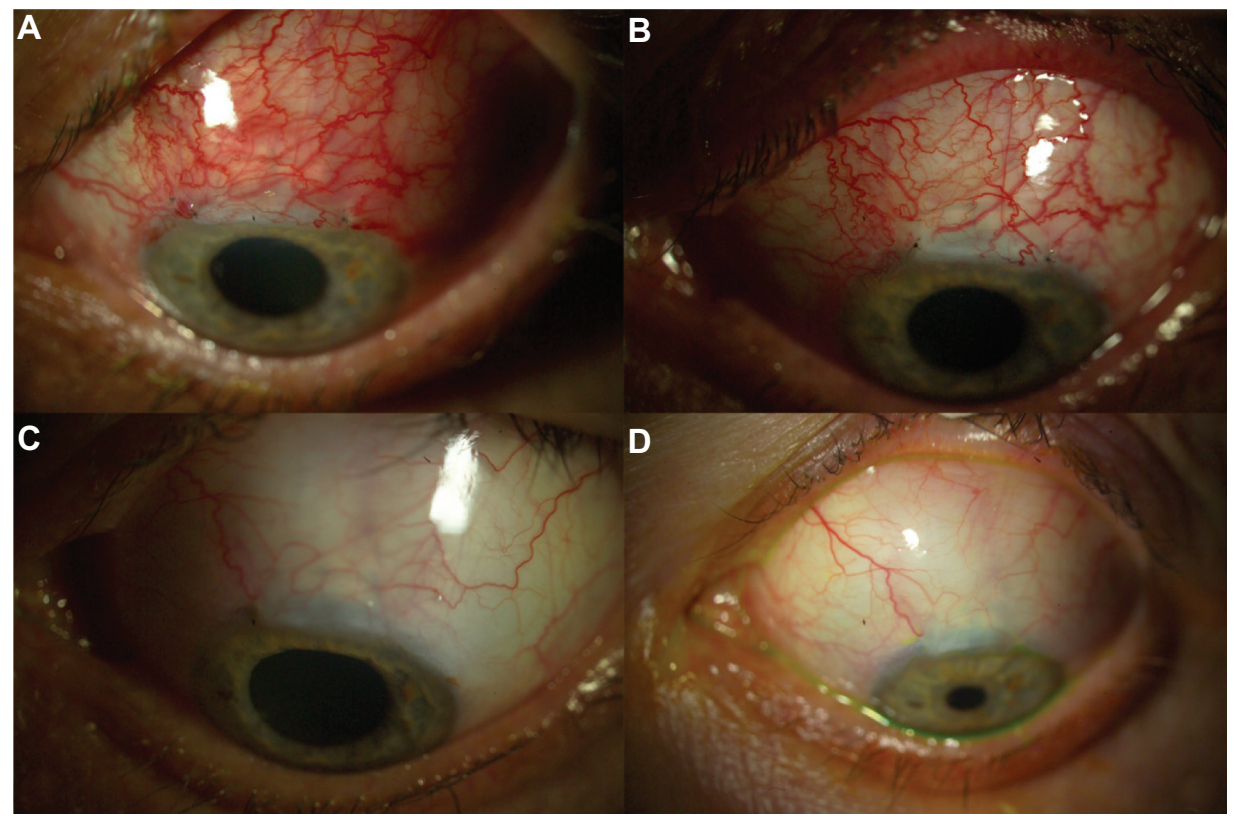

Figure 2 Unsuccessful treatment of early bleb failure with topical bevacizumab in patient 7. (A) Flat and injected bleb prior to bevacizumab application, (B) 7 days after topical administration of bevacizumab, (C) 2 months after topical administration of bevacizumab, and (D) 6 months after topical administration of bevacizumab, revealing a pale, flat, and nonfunctional bleb. 
Table 2 Intraocular pressures $(\mathrm{mmHg})$ in all of the eyes studied prior to surgery, at the beginning of treatment with bevacizumab, and at 2 and 6 months later

\begin{tabular}{|c|c|c|c|c|}
\hline Patient & IOP prior to surgery & IOP at beginning of treatment & IOP 2 months after surgery & IOP 6 months after surgery \\
\hline MP & 17 & 12 & 9 & II \\
\hline KL & 16 & 14 & 12 & 12 \\
\hline$J \mathrm{~L}$ & 31 & 34 & 2 & 4 \\
\hline $\mathrm{JB}$ & 34 & 13 & 21 & 34 \\
\hline ED & 30 & 30 & 10 & 12 \\
\hline MK & 30 & 6 & 16 & 13 \\
\hline CG & 18 & 6 & 12 & 14 \\
\hline HD & 19 & 6 & 8 & 3 \\
\hline FS & 26 & 20 & 18 & 30 \\
\hline TL & 40 & 20 & 20 & 19 \\
\hline JC & 14 & 10 & 16 & 14 \\
\hline JC & 21 & 14 & 13 & 16 \\
\hline ZS & 32 & 29 & 38 & 28 \\
\hline KW & 44 & 24 & 12 & 12 \\
\hline GN & 17 & 20 & 25 & 20 \\
\hline LK & 44 & 9 & 16 & 25 \\
\hline KK & 15 & 20 & 20 & 14 \\
\hline JL & 22 & 26 & 10 & 6 \\
\hline AK & 33 & 8 & 8 & 10 \\
\hline JC & 20 & 19 & 6 & 12 \\
\hline WA & 36 & 14 & 14 & 22 \\
\hline
\end{tabular}

Abbreviation: IOP, intraocular pressure.

despite poor bleb morphology. Bleb leak was still present on subsequent evaluations, and successful reconstruction of filtration bleb was performed six weeks postoperatively. After meticulous analysis of the literature on the possible side effects of intraocular administration of bevacizumab, along with careful assessment of the potential benefits of this agent, we subsequently elected to continue treatment despite the positive Seidel test. Accordingly, in the next case, despite a positive Seidel test being present between days 16 and 23 after surgery, topical bevacizumab was started on postoperative day 9 . In the remaining case, despite a positive Seidel test being present on the first day after surgery, topical bevacizumab was started on postoperative day 8 . The leak persisted over 18 days of treatment with bevacizumab, and secondary sutures were placed for persistent bleb leak 7 days after cessation of bevacizumab. No other side effects were noted during follow-up.

\section{Discussion}

The first several weeks after a filtration procedure are crucial for the ultimate success of treatment. Essential for efficacy is preservation of the patency of the filtration fistula created during surgery. Gentle intraoperative tissue handling and use of steroids and antifibrotic agents have been suggested to maintain the patency of this conduit, but this goal is not always attained, and postoperative inflammation and scar formation may lead to early bleb failure during the first few months after surgery. Increased vascularity and reduction in bleb height and area, with or without an increase in IOP, constitute the early signs of bleb failure. ${ }^{14}$ Prompt measures need to be taken to prevent development of permanent adhesions between the conjunctiva and episclera. Frequent use of topical or systemic corticosteroids is presently considered to be standard of care in such cases. Further, an adjunctive antimetabolite, such as 5-fluorouracil or mitomycin $\mathrm{C}$, is usually used perioperatively for further reduction of subconjunctival fibrosis. Measures such as ocular massage and/or removal of releasable sutures or laser suture lysis are further initial measures for management of this situation. However, despite all the aforementioned maneuvers, the failure rate is as high as $30 \%-40 \%$ in longterm follow-up. ${ }^{15,16}$ In the face of such a high failure rate, further treatment modalities are needed.

In our series, 16 of 21 patients (approximately 75\%) with developing bleb failure recovered, which seems to be a very high success rate, especially when compared with standard treatment (reported success rate $26 \%$ ) or subconjunctival injections of 5-fluorouracil (reported 51\% success rate) in eyes with a poor prognosis. ${ }^{17}$ Further, the remaining 25\% of blebs blanched relatively quickly, but the fistulae did not remain patent. The natural history of bleb healing involves reduction of vascularity, ${ }^{18}$ regardless of the final filtration efficacy. Importantly, nonfunctional blebs should undergo 
revision no later than 3 months because the healing process has ended by this time and no further improvement can be expected. ${ }^{19}$ Therefore, it seems that topical bevacizumab $5 \mathrm{mg} / \mathrm{mL}$ drops should either be started immediately after surgery or immediately at the first signs of bleb failure.

Wound healing in scleral tissue is physiologically similar to that in other tissues, with the exception of the blood vessels; the sclera contains very few of these, with most originating from the adjacent episclera. ${ }^{20}$ Hampered access of the vessels to the forming scar might increase the effectiveness of antiangiogenic treatment in the early postoperative period, not only immediately but also within the first week after surgery. On the other hand, most of the available data show that the neovascularization process at the surgical wound site is most vigorous during the first 2 weeks after surgery. ${ }^{21}$ Based on the aforementioned data, our therapeutic protocol of starting bevacizumab within the first 3 weeks after surgery seems to be valid. Subsequently, we administered bevacizumab for up to 6 weeks based on individual patient requirements, judged primarily by clinical signs of neovascularization. Importantly, the given time frame for the use of bevacizumab is the time when proangiogenic processes occur, in contrast with other eye-surface diseases, such as corneal neovascularization after transplant when angiogenesis is continuously perpetuated. In cases with poor bleb formation where, on top of neovascularization, one can expect extensive fibrinogen formation, additional rationale for administration of bevacizumab arises from recent publications, which provide some evidence for its anti-inflammatory and antifibroblastic effects. ${ }^{6,22}$ However, recent developments support the notion that treatment with anti-VEGF factors might cause excessive sclerosis in patients with proliferative diabetic retinopathy. ${ }^{23,24}$ Bevacizumab has been used previously in glaucoma surgery in the form of postoperative subconjunctival injections. Both animal and human studies have demonstrated this to be effective..$^{21,25}$ Similarly, intraoperative injections during revision surgeries for nonfunctional filtration blebs have been shown to increase the chances of a successful outcome. ${ }^{26}$

To the best of our knowledge, this is the first report to date of topical administration of bevacizumab for threatening bleb failure, and is a follow-up of our own findings reported in a letter published in $2011 .{ }^{27}$ In our opinion, this modality has several advantages, in that it is less traumatic, allows extended administration on an outpatient basis, and reduces the costs of therapy. Further, given the limited systemic absorption of bevacizumab in comparison with subconjunctival injections, the topical route of administration might avoid serious side effects. Oncology patients treated with systemic injections of bevacizumab suffer potentially dangerous side effects, including hypertension, emboli, hematologic disturbances, and ulceration of the mucous membranes. ${ }^{28}$ Importantly, subconjunctival and intravitreal injections result in accumulation of bevacizumab in the contralateral eye, while topical administration results in low levels of bevacizumab in the iris and retina of the ipsilateral eye. ${ }^{29}$ Moreover, no significant side effects of topical administration on the surface of the eye have been reported. ${ }^{30}$ Simultaneously, one can expect that the bevacizumab concentration in the vicinity of the scleral flap is adequate, based on existing reports of the affinity of bevacizumab for sites of neovascularization. Additionally, inflammation surrounding the postoperative wound facilitates drug bioavailablility. ${ }^{31}$ This has been demonstrated by successful use of bevacizumab drops in the treatment of corneal neovascularization. ${ }^{6}$ Accordingly, we elected to implement a similar protocol in our study.

Another important aspect of bevacizumab administration is the likelihood of impairment of conjunctival healing that might increase the risk of early bleb leaks, especially when used in conjunction with mitomycin $\mathrm{C}$, which itself has been reported to be an antiangiogenic agent. ${ }^{32}$ Importantly, in our group, we noticed some proportion of leaks (14\%), indicating that these should be treated as a potential side effect. However, our data show a significantly lower proportion of leaks when compared with other reports. ${ }^{32,33}$ Moreover, one should keep in mind that one of the reported leaks occurred before treatment with bevacizumab, while two others occurred after treatment.

Taken together, our data support the hypothesis that topical administration of bevacizumab might be beneficial in the treatment of early filtering bleb insufficiency due to increased vascularity. An important aspect of its implementation in the treatment protocol is the fact that topical application of bevacizumab does not preclude use of other standard preventive measures. However, long-term observation in a randomized, double-blind, placebo-controlled prospective study is needed to assess the safety and efficacy of this strategy.

\section{Disclosure}

The authors report no conflicts of interest in this work.

\section{References}

1. Spaeth GL. Ophthalmic Surgery: Principles and Practice. 3rd ed. Philadelphia, PA: WB Saunders Co; 2003.

2. Skuta GL, Parrish RK 2nd. Wound healing in glaucoma filtering surgery. Surv Ophthalmol. 1987;32:149-170.

3. Li J, Chen J, Kirsner R. Pathophysiology of acute wound healing. Clin Dermatol. 2007;25:9-18. 
4. Ma J, Waxman DJ. Combination of antiangiogenesis with chemotherapy for more effective cancer treatment. Mol Cancer Ther. 2008; 7:3670-3684.

5. Grisanti S, Ziemssen F. Bevacizumab: off-label use in ophthalmology. Indian J Ophthalmol. 2007;55:417-420.

6. Bock F, Konig Y, Kruse F, Baier M, Cursiefen C. Bevacizumab (Avastin) eye drops inhibit corneal neovascularization. Graefes Arch Clin Exp Ophthalmol. 2008;246:281-284.

7. Lalwani GA, Berrocal AM, Murray TG, et al. Off-label use of intravitreal bevacizumab (Avastin) for salvage treatment in progressive threshold retinopathy of prematurity. Retina. 2008;28:S13-S18.

8. Grisanti S, Biester S, Peters S, Tatar O, Ziemssen F, BartzSchmidt KU. Intracameral bevacizumab for iris rubeosis. Am J Ophthalmol. 2006;142:158-160.

9. Fallah MR, Khosravi K, Hashemian MN, Beheshtnezhad AH, Rajabi MT, Gohari M. Efficacy of topical bevacizumab for inhibiting growth of impending recurrent pterygium. Curr Eye Res. 2010;35:17-22.

10. Jurkowska-Dudzinska J, Kosior-Jarecka E, Zarnowski T. Comparison of the use of 5-FU and bevacizumab in primary trabeculectomy: results at one year. Clin Experiment Ophthalmol. 2012;40:135-142.

11. Bakri SJ, Cameron JD, McCannel CA, Pulido JS, Marler RJ. Absence of histologic retinal toxicity of intravitreal bevacizumab in a rabbit model. Am J Ophthalmol. 2006;142:162-164.

12. Bock F, Konig Y, Dietrich T, Zimmermann P, Baier M, Cursiefen C. Inhibition of angiogenesis in the anterior chamber of the eye. Ophthalmologe. 2007;104:336-344. German.

13. Cantor LB, Mantravadi A, WuDunn D, Swamynathan K, Cortes A. Morphologic classification of filtering blebs after glaucoma filtration surgery: the Indiana Bleb Appearance Grading Scale. J Glaucoma. 2003;12:266-271.

14. Azuara-Blanco A, Katz LJ. Dysfunctional filtering blebs. Surv Ophthalmol. 1998;43:93-126.

15. Jampel HD, Solus JF, Tracey PA, et al. Outcomes and bleb-related complications of trabeculectomy. Ophthalmology. 2012;119: 712-722.

16. Landers J, Martin K, Sarkies N, Bourne R, Watson P. A twentyyear follow-up study of trabeculectomy: risk factors and outcomes. Ophthalmology. 2012;119:694-702.

17. [No authors listed]. Three-year follow-up of the Fluorouracil Filtering Surgery Study. Am J Ophthalmol. 1993;115:82-92.

18. Hollo G. Wound healing and glaucoma surgery: modulating the scarring process with conventional antimetabolites and new molecules. Dev Ophthalmol. 2012;50:79-89.

19. Feldman RM, Tabet RR. Needle revision of filtering blebs. J Glaucoma. 2008;17:594-600.
20. American Academy of Ophthalmology. Fundamentals and Principles of Ophthalmology, 2000-2001. San Francisco, CA: American Academy of Ophthalmology; 2000.

21. Coote MA, Ruddle JB, Qin Q, Crowston JG. Vascular changes after intra-bleb injection of bevacizumab. J Glaucoma. 2008;17:517-518.

22. Kim TI, Chung JL, Hong JP, Min K, Seo KY, Kim EK. Bevacizumab application delays epithelial healing in rabbit cornea. Invest Ophthalmol Vis Sci. 2009;50:4653-4659.

23. Batman C, Ozdamar Y. The effect of bevacizumab for anterior segment neovascularization after silicone oil removal in eyes with previous vitreoretinal surgery. Eye (Lond). 2010;24:1243-1246.

24. Kuiper EJ, Van Nieuwenhoven FA, de Smet MD, et al. The angiofibrotic switch of VEGF and CTGF in proliferative diabetic retinopathy. PLoS One. 2008;3:e2675.

25. Memarzadeh F, Varma R, Lin LT, et al. Postoperative use of bevacizumab as an antifibrotic agent in glaucoma filtration surgery in the rabbit. Invest Ophthalmol Vis Sci. 2009;50:3233-3237.

26. Kahook MY, Schuman JS, Noecker RJ. Needle bleb revision of encapsulated filtering bleb with bevacizumab. Ophthalmic Surg Lasers Imaging. 2006;37:148-150.

27. Zarnowski T, Tulidowicz-Bielak M. Topical bevacizumab is efficacious in the early bleb failure after trabeculectomy. Acta Ophthalmol. 2011;89:605-606.

28. Eskens FA, Verweij J. The clinical toxicity profile of vascular endothelial growth factor (VEGF) and vascular endothelial growth factor receptor (VEGFR) targeting angiogenesis inhibitors; a review. Eur J Cancer. 2006;42:3127-3139.

29. Nomoto H, Shiraga F, Kuno N, et al. Pharmacokinetics of bevacizumab after topical, subconjunctival, and intravitreal administration in rabbits Invest Ophthalmol Vis Sci. 2009;50:4807-4813.

30. Bock F, Onderka J, Rummelt C, et al. Safety profile of topical VEGF neutralization at the cornea. Invest Ophthalmol Vis Sci. 2009;50: 2095-2102.

31. Feiner L, Barr EE, Shui YB, Holekamp NM, Brantley MA Jr. Safety of intravitreal injection of bevacizumab in rabbit eyes. Retina. 2006;26:882-888.

32. Anand N, Arora S, Clowes M. Mitomycin C augmented glaucoma surgery: evolution of filtering bleb avascularity, transconjunctival oozing, and leaks. Br J Ophthalmol. 2006;90:175-180.

33. Alwitry A, Rotchford A, Patel V, Abedin A, Moodie J, King AJ. Early bleb leak after trabeculectomy and prognosis for bleb failure. Eye (Lond). 2009;23:858-863.
Clinical Ophthalmology

\section{Publish your work in this journal}

Clinical Ophthalmology is an international, peer-reviewed journal covering all subspecialties within ophthalmology. Key topics include: Optometry; Visual science; Pharmacology and drug therapy in eye diseases; Basic Sciences; Primary and Secondary eye care; Patient Safety and Quality of Care Improvements. This journal is indexed on

\section{Dovepress}

PubMed Central and CAS, and is the official journal of The Society of Clinical Ophthalmology (SCO). The manuscript management system is completely online and includes a very quick and fair peer-review system, which is all easy to use. Visit http://www.dovepress.com/ testimonials.php to read real quotes from published authors. 